Aldo Raúl Díaz Medina

50 


\section{Antecedentes de la dialéctica y el rompimiento hegeliano}

\section{Introducción}

A través de la historia del pensamiento, el vocablo dialéctica se puede entender a grandes rasgos como un término derivado del diálogo; no obstante, éste no tiene una significación universal o constante; sobre esto, Enrique Dussel comenta que: "Distintas son las dialécticas porque distintas son las épocas en que fueron formuladas en la historia del pensar". Pero esta multiplicidad de significados no representa el uso indiscriminado y egoísta del término, pues la complejidad y multiplicidad de formulaciones son resultado de su uso a lo largo de la historia del pensamiento humano. Como ejemplo podemos tomar a Hegel, representante de uno de los últimos pensamientos sistemáticos de la filosofía, que encuentra su piedra angular dentro de la dialéctica. La dialéctica se remonta en sus inicios a tiempos de los pensadores griegos, y su desarrollo atraviesa grandes etapas del mismo pensamiento filosófico, por tanto, es de importancia no sólo concebir dentro del desenvolvimiento del presente trabajo el esbozo de un concepto hegeliano, sino introducir ese esfuerzo mediante la discusión de la formación del concepto dialéctico desde sus inicios.

Captar la modificación sobre su concepción a lo largo de diferentes épocas adquiere un carácter importante. Situarnos en el abordaje de un concepto momificado correspondería a contraer una inmensidad de problemas, pues es claro que no comprendemos la mayoría del lenguaje y su conceptualización dentro de los mismos sitios en los que apenas hace un siglo se realizaban. El desplazamiento de los conceptos dentro de la historia del pensamiento filosófico es ya un carácter natural al que el filósofo tiene que adherirse dentro de las representaciones y reflexiones que intente plasmar; dejar de lado o minimizar la adquisición de un concepto dentro de un momento circunstancial de su formación podría repercutir dentro del análisis final del concepto. Por tanto, es necesario no sólo introducirse en el concepto de dialéctica en un momento dado, sino darse a la tarea de entender el origen y el de-

\footnotetext{
E. Dussel, La Dialéctica Hegeliana, Editorial Ser y Tiempo, Argentina, 1972, p. 10.
} 
sarrollo del mismo, así como su modificación dentro de las diferentes épocas del pensamiento.

La dialéctica encuentra su forma actual dentro del pensamiento de Hegel, nuestro principal objetivo es saber que adquiere su origen siempre en relación con postulados anteriores; esto es algo que no se puede negar, han dejado de ser el concepto platónico, aristotélico o fichteano de dialéctica la base del actual concepto. La finalidad de adquirir una forma particular de la dialéctica dentro del pensamiento hegeliano repercute directamente con el ejercicio del pensamiento, pues "como veremos, es un método o un camino, un movimiento, radical e introductorio a lo que las cosas son". ${ }^{2}$

Esta forma tan particular del pensamiento hegeliano se postula como un rompimiento, crucial en referencia con la dialéctica que se venía dando anteriormente a Hegel. Esto no significa que Hegel reinvente el concepto, sino que a partir de una considerable recopilación de los antecedentes de la dialéctica, podemos encontrar lo que se abordará posteriormente dentro del aspecto del Movimiento Dialéctico. Pero sólo se podrá lograr esta tarea atendiendo a comprender el rompimiento propuesto por Hegel en referencia a sus antecesores. Atender a la revisión de este rompimiento representa el intento por comprender: ¿¿n qué se aleja o se acerca a sus antecesores?, ¿̨por qué?, y ¿en dónde?

\section{La dialéctica platónica}

Atendiendo a la necesidad de encontrar un momento concreto para hablar del surgimiento de la dialéctica, se va a comenzar dentro del pensamiento platónico, esto, por un par de razones: la primera corresponde al hecho de encontrar dentro del corpus platónico las prístinas referencias al ejercicio dialéctico en forma escrita. Aquí se podría argumentar un carácter dialéctico antecedente al pensamiento platónico, anterior al momento en que Platón conoce a Sócrates, de quien recibe una inmensa tradición filosófica; también podemos hablar de la distinguida educación que recibe él, esto gracias a la cómoda posición de la cual disfrutaba dentro de la aristocracia griega. Dicha educación

2 Ibid, p. 10 . 
es factor importante que imprimirá un acercamiento directo de Platón con la filosofía de Heráclito, esto a través de las enseñanzas de Crátilo.

La idea para rescatar es que Platón no puede ser señalado como fundador del ejercicio dialéctico. En su déficit podríamos postular a Sócrates como el principal personaje ejercitado en el método, pero esto también dejaría de lado el pensamiento presocrático que recae sobre los hombros de Platón. No obstante, Dussel menciona al respecto que "ellos [haciendo referencia a los presocráticos] ordenaban ya los contrarios en listas orgánicas: frío-caliente, alto-bajo, ocultodesoculto $[\ldots]$ y pensaban a partir de ellos,"3 lo cual hace referencia a una parte característica del pensamiento dialéctico, y nos lleva a la formulación de una pregunta importante para dar con el origen del concepto dialéctico: ¿Por qué no empezar a partir del pensamiento presocrático? La razón principal es que, justamente no hay un acervo bibliográfico óptimo para el rescate del tema. $Y$ aunque no fuera contemplada la particularidad del tema, aun así se tendría que lidiar con la escasez de los textos, o el hecho de que los pocos que se han recuperado son textos incompletos donde lo que viene a resaltar más que nada es el trabajo interpretativo de filólogos y otros especialistas.

La segunda razón por la cual nos hemos conducido de esta forma es porque en Platón es posible rescatar los primeros indicios de un abordaje sobre el concepto de dialéctica como tal. Cuando Platón habla de dialéctica está tratando de especificar un ejercicio bien definido, y no una exploración de las posibilidades o una mirada ciega que se conduce a tientas para apenas especular sobre ciertas reflexiones. El pensamiento dialéctico que hace de suyo Platón contiene ya el bagaje de la tradición presocrática, pero la forma de exposición y definición que se da a través de los Diálogos de Platón es comparable al barro que ha tomado forma para demostrar que no es sólo una mezcla de agua y tierra, y que con su uso es posible la construcción de un sinnúmero de posibilidades. Esta última idea puede ser tan criticable como la primera, pero en función de buscar un terreno aunque no sea del todo plano para el desarrollo del concepto dialéctico, situarnos dentro del corpus platónico establece que nuestros primeros pasos dentro de este recorrido no sean en terreno pantanoso.

Justamente se ha mencionado que el terreno platónico dentro del desarrollo dialéctico no es plano, ¿por qué? El análisis de los tex-

$3 \quad$ Ibid, p. 13. 
tos platónicos ha arrojado una idea clara sobre dos momentos dentro del pensamiento filosófico de Platón, el primero correspondiente a su convivencia con el que sería su introductor y maestro en la filosofía, Sócrates, este momento se distinguirá por la búsqueda de las virtudes dentro de sus Diálogos; pero también existe un segundo momento donde se visualiza un Platón en su etapa madura, un Platón más arraigado a sus ideas políticas. Al igual que existen dos momentos, los cuales se podrían señalar como la etapa del Platón joven y el Platón maduro, también es posible hablar de dos dialécticas, cada una correspondiente a las etapas indicadas. La visión general del pensamiento platónico apunta a distinguir dichas dialécticas, pero antes de dividir el trayecto a realizar, se puede señalar un origen común, pues, tal como lo señala Vaderrey en su Historia del pensamiento, el concepto de dialéctica, sobre el cual se apoya Platón, proviene "del griego'Día, a través 'leguein' decir. La dialéctica etimológicamente se halla relacionada con el diálogo, en orden a conseguir la verdad". ${ }^{4}$ A partir de su significado epistemológico es posible distinguir características importantes, no sólo de un concepto platónico, sino del concepto general en el desarrollo del pensamiento.

La preeminencia en el uso de la palabra griega que hace referencia al "día" contiene una estrecha relación con la jerarquía de las ideas que postula Platón, pues la idea de "bien" ocupa el lugar más alto de la escala, es frecuentemente comparada con la idea de Sol, siendo esto un referente concreto de lo que el objetivo del método desea alcanzar, es decir, la idea más alta. Desde este punto ya es visible una primera aproximación a la dialéctica como un método ascendente, pero también con un objetivo muy claro, el de alcanzar una idea más elevada.

El segundo componente del constructo nos habla sobre la forma del método. El carácter particular en el 'decir' puede provenir todavía de una profunda desconfianza del método escrito, pues no sólo es de subrayar que la comunicación oral fungía casi como la totalidad del aparato comunicativo dentro de la época helénica. La gran capacidad de memoria dentro de los griegos se atribuía como un gran talento, ya que quien retuviera una mayor cantidad de conocimientos exactos, sobre los temas más variados, tendría más oportunidad de dar

4 T. Lobato Valderrey, Historia del pensamiento, Dykinson, Salamanca, 2001, p. 59. 
argumentos citando a algún pensador de respeto, esto era algo importante dentro de las discusiones que se realizaban en el Ágora.

Si bien la desconfianza del lenguaje escrito que terminaba por generar poca utilidad o funcionalidad dentro de la vida de la antigua Grecia no parece ser suficiente argumento para sostener la importancia del "decir", aparece la mayéutica socrática como la conformación del diálogo bajo un objetivo: dar a luz a una idea, esto sólo a partir del "decir". La mayéutica, método interrogativo de carácter inductivo, usado por Sócrates, se presenta como uno de los métodos más importantes dentro de la Filosofía, su característica principal es la formulación de un diálogo a través del "decir". Este método puede ser dividido en tres momentos diferentes: el primero es aquél donde se define un tema de interés para los dialogantes; en esta parte comúnmente Sócrates se admitía como ignorante pero, sólo para asumir el principio o definición de su dialogante; el segundo se puede admitir como un momento de negación, por medio de la ironía, pues aunque ya había sido expuesta una afirmación sobre el tema a discutir, Sócrates empieza a reducir las afirmaciones ya expuestas, lo que terminaría siendo una contradicción, este periodo en general permitía dejar al descubierto la ignorancia del dialogante, que en un primer término sólo Sócrates había aceptado, es en este momento cuando podría decirse que el dialogante puede permitir la ayuda de Sócrates para ir en busca de la definición; Sócrates cumple con su parte de comadrona en el tercer momento, pues gracias a su forma de interrogar, el dialogante puede dar a luz a la idea. La última parte del método tiene cierta relación con la teoría platónica de la existencia de las ideas innatas, pero también podemos atribuirle responsabilidad a la búsqueda de la verdad dentro de uno mismo, pues no por nada se le atribuye a Sócrates la frase: "Conócete a ti mismo". En resumen, el proceso mayéutico contiene una semejanza innegable con la dialéctica hegeliana, ambos acuden a un proceso de tres pasos: una afirmación, la negación de ésta, y por último, una superación que asciende a un nuevo nivel. El paralelismo entre los métodos no es total, pero un primer acercamiento denota ya la estrechez del concepto hegeliano y al que podríamos llamar el "método socrático".

Señalado este punto clave dentro de la formación dialéctica, es posible avanzar un poco. Ya se ha hecho hincapié sobre la posible influencia socrática con base en la forma del método, pero esto no es todo, tomando en cuenta el uso de la dialéctica, es posible abordar 
un tópico muy diferente dentro de la vida griega, pues no es en exclusivo del filósofo el uso que hacía de tan importante método. "Fueron sin embargo los sofistas del tiempo de Sócrates que se constituyeron en maestros de la dialéctica, pero en el sólo sentido de arte de la refutación", ${ }^{5}$ con lo cual se descubre una idea de dialéctica centrada en aquella capacidad de contradicción en el "decir". La capacidad de llevar de un lado a otro el razonamiento deseado toma una forma bastante particular dentro del pensamiento sofista, pero a su vez, "La dialéctica era un arte necesario principalmente para el político, para saber defender su opinión y criticar la contraria en el Ágora." Se sustituye así la visión epistemológica de la dialéctica ascendente rescatada dentro del pensamiento socrático por la imposición de una dialéctica más preocupada en el convencer del "decir" qué, en el objetivo de llegar a la luz de la verdad cognitiva que en un principio se visualizó. La diferencia abismal entre el uso y objeto de la dialéctica de estas posturas queda plasmada dentro de la obra platónica. Obviamente, el mismo Platón observa y discierne estas formas, a tal punto que nos advierte sobre la versión de la dialéctica de los sofistas: "¿No te percatas de cuán grande llega a ser el mal relativo a la dialéctica en la actualidad?"?

La opinión negativa que da Platón de los sofistas es clara, pero no deja de ser una aportación en la formulación del concepto, pues en tanto que desacredita su uso, asume la constitución de la dialéctica como un método que parte del "decir", característica que comparte con los sofistas, pero para alejarse cuando ésta se sitúa con la impetuosa necesidad de la transmisión oral de una idea de conveniencia pero con escaso de sentido.

El "decir" rescatado por Platón recupera también el logos en el "decir" común, esto como razón o facultad ordenadora que acerca al hombre al mundo de las ideas, lo hace por la vía del discernimiento de las ideas, separando las puras, de las impuras. Cito un pequeño párrafo del diálogo que lleva por título el "Sofista", donde Platón hace referencia al ejercicio dialéctico bajo su forma de discernimiento analítico: "Quien es capaz de hacer esto: distinguir [A] una sola forma que se extiende por completo a través de muchas, que están, cada una de ellas, separada; y [B] muchas, distintas las unas de las otras, rodea-

5 E. Dussel, op cit., p. 14.

6 Ibid, p. 14.

7 Platón, Diálogo IV (República), Gredos, España, 2008, p. 374. 
das desde fuera por una sola; y [C] una sola pero constituida ahora en una unidad a partir de varios conjuntos; [D] muchas diferenciadas".

El discernimiento de esta dialéctica corresponde al análisis de la formación del lenguaje, pues el método como tal no puede prescindir de su conformación en el lenguaje. Platón lo recalca, en cómo se maneja el método, como la distinción y separación de los géneros: "quien es capaz de esto, repito, sabe distinguir, respecto de los géneros, cómo algunos son capaces de comunicarse con otros y cómo no." Pero esta caracterización de la dialéctica platónica correspondería todavía a la etapa socrática, la problemática a la que aparece enfocado el método todavía prevalece en el ámbito de la distinción de los contrarios. El tema al que se sujeta todavía es la superación de la dialéctica de los sofistas, esto bajo la perfecta definición del método dialéctico en la clara distinción de los géneros.

La otra caracterización de la dialéctica dentro del planteamiento platónico corresponderá a una etapa en que Platón va en búsqueda de un ideal político, parte fundamental de este tema es la idea del filósofo-rey y su formación:

Y una vez llegados a los cincuenta de edad, hay que conducir hasta el final a los que hayan salido airosos de las pruebas y se hayan acreditado como los mejores en todo sentido, tanto en los hechos como en los disciplinas científicas, y se les debe forzar a elevar el ojo del alma para mirar hacia lo que proporciona Luz a todas las cosas; $y$, tras ver el Bien en sí, sirviéndose de éste como paradigma, organizar durante el resto de sus vidas el Estado. ${ }^{10}$

En el texto de la República se asigna la tarea de plasmar una teoría política, parte importante de la obra hace referencia a la educación que tiene que llevar a cabo aquel individuo capaz de gobernar. En esta última etapa de la formación del gobernante es donde Platón insistirá en que se ejercite el método dialéctico: "Bastará, entonces, con que permanezcan aplicados a la dialéctica de modo serio y perseverante, no haciendo ninguna otra cosa" ${ }^{11} \mathrm{La}$ insistencia de que el

\footnotetext{
8 Platón, Diálogos V (Sofista), op cit., pp. 433 y 434.

9 Ibid, p., 434.

10 Platón, Diálogos IV (República), op cit., p. 375.

11 Idem.
} 
filósofo-rey se ejercite casi únicamente en el ejercicio dialéctico denota la importancia que asume el método, pero ya no es el mismo método comentado en líneas anteriores, la nueva importancia se explica bajo la nueva conceptualización que tiene la dialéctica, ésta ya aparece alejada de aquella simple distinción de los contrarios.

El carácter principal de esta nueva constitución dialéctica sigue una línea epistemológica, pero adquiere el sentido último y más pleno con el ascenso al conocimiento del Bien, pues a partir de este conocimiento, el gobernante puede tener la capacidad de gobernar la Polis. "Por la dialéctica se llega al último grado intelectual o intuición (noein) de las Ideas", ${ }^{12}$ el sentido del método platónico ha trascendido de una mera distinción de los géneros al conocimiento pleno del Bien; el método así alcanza un sentido epistemológico de plenitud comparable con el sentido de dialéctica en Hegel. A este respecto, Dussel comenta que "Se trata entonces del método supremo y último; para nosotros, en cambio -para Hegel-, será el método supremo pero primero, inicial, anterior a las ciencias y no posterior a ellas." ${ }^{13}$

$\mathrm{Al}$ resumir lo expuesto con anterioridad, se puede señalar que es fácil encontrar una semejanza entre la dialéctica platónica y la hegeliana; es claro que la segunda no aplica explícitamente lo rescatado dentro del presente texto como método, pues sus diferencias trasgreden hasta cierto punto la interpretación tanto de la forma como del objetivo dialéctico en lo que sería el pensamiento hegeliano. Aun así, es innegable que los rastros que se han querido rescatar aquí son parte del esqueleto de la dialéctica hegeliana. La conclusión final que se puede obtener del análisis de la dialéctica platónica es la formulación de dos formas específicas de la dialéctica, ambas son referente obligado de la dialéctica hegeliana, pero una idea más importante aún es que estas dos formas abren camino a dos senderos de gran importancia para el pensamiento dialéctico dentro de la Filosofía.

\section{Dialéctica aristotélica}

El origen de la dialéctica no es netamente platónico, esto queda claro en la primera parte del artículo, pero en la búsqueda del antecedente

12 E. Dussel., op cit., p. 14.

13. Idem. 
más antiguo es necesario aceptar que remitirnos a Platón es la mejor opción para los objetivos de la investigación. Tomando en cuenta esto, el camino de la dialéctica se conducirá por dos senderos totalmente contrarios, el primero recae bajo la tradición medieval y su forma de comprender el concepto dialéctico; y el segundo, el que utilizará el concepto como principio de una forma de razonamiento, tal y como Aristóteles defendió.

El sendero que recorrerá la tradición medieval se centrará bajo el concepto de dialéctica en un sentido dogmático, pues estos (los medievales) se situaban en la clara idea de que la dialéctica es un sistema de ascensión a la verdad, a lo Uno, en otras palabras: a Dios. Las formas del pensamiento presentadas dentro de la Alta Edad Media recaen en figuras como San Agustín de Hipona, Plotino, Dionisio Aeropagita, entre otras, pensadores que tienen diferentes preocupaciones, pero que entran dentro de un mismo bosquejo de hacer filosofía. Su trabajo se sitúa tanto bajo la exigencia de un rescate del pensamiento platónico como de la misma introspección. En esta forma de pensamiento no se desarrolla un cuestionamiento o análisis sobre lo que es o lo que no es tal y como el pensamiento aristotélico intentará desarrollar, por el contrario, la forma de razonamiento intenta demostrar que lo que es, es lo verdadero. La demostratio medieval versa en una forma de búsqueda positiva del ignoto. Es entonces el conocimiento del Dios lo que funge aquí como fin último del ejercicio dialéctico, ya no por razonamiento sino por iluminación divina. $\mathrm{Al}$ respecto, Dussel comenta que: "La dialéctica plotiniana será igualmente positiva (en tanto gnosis), pero postulará ya la negatividad como exigencia para recuperar la ascensión la simplicidad inicial del Uno degradado". ${ }^{14}$

En el razonamiento dialéctico sigue apareciendo el forzoso paso de lo que es y lo que no es, de lo Uno y lo Múltiple (Plotino), pero la negatividad en el proceso de la ascensión de la gnosis se presentará como propio del argumento de la existencia de lo Uno, de Dios. En este caso el Dios de los cristianos sólo podría ser demostrado por medio de la docta ignorancia, pues tal como lo señalan sus razonamientos, sólo podemos alcanzar la gnosis del ignoto si sabemos que él es absolutamente diferente de la forma que conocemos y por tanto

14 Ibidem., p. 15. 
más antiguo es necesario aceptar que remitirnos a Platón es la mejor opción para los objetivos de la investigación. Tomando en cuenta esto, el camino de la dialéctica se conducirá por dos senderos totalmente contrarios, el primero recae bajo la tradición medieval y su forma de comprender el concepto dialéctico; y el segundo, el que utilizará el concepto como principio de una forma de razonamiento, tal y como Aristóteles defendió.

El sendero que recorrerá la tradición medieval se centrará bajo el concepto de dialéctica en un sentido dogmático, pues estos (los medievales) se situaban en la clara idea de que la dialéctica es un sistema de ascensión a la verdad, a lo Uno, en otras palabras: a Dios. Las formas del pensamiento presentadas dentro de la Alta Edad Media recaen en figuras como San Agustín de Hipona, Plotino, Dionisio Aeropagita, entre otras, pensadores que tienen diferentes preocupaciones, pero que entran dentro de un mismo bosquejo de hacer filosofía. Su trabajo se sitúa tanto bajo la exigencia de un rescate del pensamiento platónico como de la misma introspección. En esta forma de pensamiento no se desarrolla un cuestionamiento o análisis sobre lo que es o lo que no es tal y como el pensamiento aristotélico intentará desarrollar, por el contrario, la forma de razonamiento intenta demostrar que lo que es, es lo verdadero. La demostratio medieval versa en una forma de búsqueda positiva del ignoto. Es entonces el conocimiento del Dios lo que funge aquí como fin último del ejercicio dialéctico, ya no por razonamiento sino por iluminación divina. $\mathrm{Al}$ respecto, Dussel comenta que: "La dialéctica plotiniana será igualmente positiva (en tanto gnosis), pero postulará ya la negatividad como exigencia para recuperar la ascensión la simplicidad inicial del Uno degradado". ${ }^{14}$

En el razonamiento dialéctico sigue apareciendo el forzoso paso de lo que es y lo que no es, de lo Uno y lo Múltiple (Plotino), pero la negatividad en el proceso de la ascensión de la gnosis se presentará como propio del argumento de la existencia de lo Uno, de Dios. En este caso el Dios de los cristianos sólo podría ser demostrado por medio de la docta ignorancia, pues tal como lo señalan sus razonamientos, sólo podemos alcanzar la gnosis del ignoto si sabemos que él es absolutamente diferente de la forma que conocemos y por tanto

14 Ibidem., p. 15. 
de la forma en que comprendemos; en otras palabras, se encuentra fuera de nuestro entendimiento.

Esta forma del pensamiento dialéctico tendría una gran aceptación dentro del pensamiento medieval; sin embargo, y antes de que esto sucediera, ya "Aristóteles plantea la cuestión en un sentido muy distinto al de su maestro Platón" ${ }^{15}$ El sentido dialéctico de la época medieval se distingue por una gnosis ascendente, lo cual sigue planteando al ejercicio dialéctico en un sentido epistémico, tomando como dogma el discurso platónico, algo con lo que Aristóteles no estará de acuerdo.

El sentido de la dialéctica aristotélica partirá más como un ejercicio de razonamiento dentro del lenguaje, y su función se establecerá más como un método que como fin. Una primera diferenciación es su punto de partida; al respecto, Dussel menciona que "El punto de partida no es una premisa cierta sino opinión cotidiana', algo que el platonismo pensó despreciable." ${ }^{16} \mathrm{Y}$ justamente es despreciable, porque éste no puede ser cuestionable.

Para poder entender esto, es necesario ver la crítica de Aristóteles sobre su maestro Platón, de tal manera que se pueda visualizar la construcción del concepto. La mejor forma de comprender esto es mediante las mismas palabras que Aristóteles expone en su Tratado de Lógica, la primera afirmación del concepto postula que:"es dialéctico el razonamiento construido a partir de cosas plausibles." ${ }^{17}$ Bajo esta afirmación ya podemos tener en cuenta cuestiones importantes, por ejemplo, que Aristóteles establece dicho concepto como razonamiento, y que su punto inicial se encuentra en las formas de la opinión cotidiana, en lo plausible de la vida. Esta descripción del método aparece de manera reiterada en su Tratado de Lógica, donde trata de indicar el principio tan simple del cual parten nuestros razonamientos, pues aquí ya no hay un fundamento verdadero e incuestionable sobre la dialéctica como lo había señalado Platón. En el análisis aristotélico, el punto de partida tanto para los razonamientos como para la ciencia será una construcción a partir de la éndoxa, la cual es una forma de opinión que parte de lo comprendido existencialmente, lo que nos arroja a las primeras formulaciones de lo que hoy conocemos como

15 Ibidem., p. 16.

16 Ibid, p. 18.

17 Aristóteles, Tratado de Lógica (Órganon I), Gredos, Madrid, 1988, p. 90. 
ciencia, pues no es difícil distinguir que es propiamente de esta forma del método en donde lo que importa es lo conocido por evidencia y no el dogma de la tradición. Es en este sentido donde Aristóteles se aleja completamente del planteamiento platónico; Dussel nos menciona al respecto lo que significaba para Platón la opinión, "La Dóxa platónica era sólo lo opinable', lo negativo y hasta despreciable. En cambio, ahora, el método supremo parte de la éndoxa, es decir, de lo cotidiano, de lo comprendido existencialmente". ${ }^{18}$ Esto comienza a perfilar un método, que es propio a sí mismo, pues "La dialéctica, entonces, argumenta, pero según un método propio. ${ }^{19}$ No existe entonces un principio a priori al cual responder, de hecho, esto corresponde a la parte integral de la forma de conocimiento en el ejercicio dialéctico, pues al no haber una verdad o fundamento fijo, la reflexión retorna a sí misma en un movimiento que viene y va, pero siempre criticando y reformulando su principio.

Ahora bien, no nos adelantemos del todo. La idea que corresponde de dialéctica en Aristóteles aparece principalmente como una forma de razonamiento y una forma de agrupación, pero ¿̇a qué se hace referencia cuando se dice razonamiento y a qué cuando es agrupamiento? La idea sobre lo que es un razonamiento es algo bastante simple, Aristóteles menciona que "Un razonamiento es un discurso (lógos) en el que sentadas ciertas cosas, necesariamente se da a la vez, a través de lo establecido, algo distinto de lo establecido, ${ }^{20}$ con lo que se postula una metodología bastante específica a seguir para llegar a un objetivo específico. La función del razonamiento aparece como un método a seguir a partir de la afirmación de algo, y con la finalidad de alcanzar una conclusión diferente, esto prácticamente será lo que posteriormente en la modernidad se establecerá con Kant como los juicios sintéticos, cuestión que por el momento sólo es importante señalar como dato importante de la aportación que realiza Aristóteles dentro de su dialéctica. Si remitimos estas especificaciones, el método se vuelve un medio, un medio que tiene como objeto el conocimiento, y es esto lo que centralmente me interesa, pues en tanto las consideraciones inicialmente aceptadas se adoptan como premisas éstas son dependientes de todo un contenido de comprensión, pero

18 E. Dussel, op cit., p. 17.

19 Idem.

20 Aristóteles, op cit., p. 90. 
no para quedarme estancado ahí, sino para un objetivo último, el cual es la extensión o ampliación del conocimiento a partir de las premisas. Hasta este punto sólo se ha hecho referencia a lo correspondiente de lo que se puede llamar "proposición dialéctica", la cual es una afirmación que busca expandir el conocimiento mediante un discernimiento. Dentro del trabajo analítico de Aristóteles es importante apreciar que también surge una problemática sobre las cuestiones contrarias, el problema dialéctico.

Un problema dialéctico es la consideración de una cuestión, tendiente, bien al deseo y al rechazo, bien a la verdad y el conocimiento, ya sea por sí misma, ya como instrumento para alguna otra cuestión de este tipo, acerca de la cual, o no se opina ni de una manera ni de otra, o la mayoría opina de forma contraria a los sabios. ${ }^{21}$

En este punto es donde aparece la preocupación por la distinción de los contrarios, se puede apreciar cierta influencia platónica, pues la preocupación se plantea desde una dificultad en ambos sentidos; discernir lo verdadero y lo falso en cada caso es lo que se puede postular dentro de lo que he manejado como la delimitación de los géneros.

Conforme a esto, la dialéctica aristotélica también se visualiza desde una postura sofística, la cual se tiene que prever para no caer en una contradicción, estas cuestiones se abordarán más profundamente en el texto Argumentos sofísticos, donde se establece que el fin de los argumentos dialécticos es llegar a una contradicción, pero aquí hay una forma de entender la contradicción como algo que se recha$z a, y$ por tanto sólo una de las afirmaciones puede prevalecer, es en este sentido, tal vez, donde entra Aristóteles en mayor relación con su maestro Platón, y es justamente donde se aleja de la formulación que después Hegel establecerá.

Algo importante dentro de los postulados aristotélicos y posteriormente los hegelianos en referencia a la dialéctica será su uso; mientras que Aristóteles ve completamente separado el ejercicio dialéctico y la ciencia, Hegel puntualizará que la única forma por la cual se llega a la ciencia primera, de hecho, es la dialéctica. Esto se debe a que la ciencia que aparece postulada por el pensador clásico se en-

${ }^{21}$ Ibid., p. 106. 
cuentra basada en que él llamará lo apodíctico, un principio verdadero por el cual se sustenta todo el conocimiento, mientras que la práctica hegeliana se remite a la comprensión de lo cotidiano. Esta idea sobre el conocimiento cotidiano es lo que posteriormente llamaremos experiencia de la conciencia.

Para concluir, se puede decir que la postura de Aristóteles se presenta como un análisis con más variantes sobre la forma dialéctica, pero deja entrever que el uso más apremiante y al que le atribuye más valor es a la forma de razonamiento que deja lo que antes no era visible; es atrevido señalar aquí que la dialéctica se empieza a perfilar como un ejercicio fenomenológico, y lo más asombroso del discurso es que se asume una apremiante confianza a fundamentar una ciencia desde el conocimiento cotidiano, algo que seriamente entra en conflicto con los postulados epistemológicos más recientes del discurso dialéctico. 